\title{
Los 13 Principios de la Declaración de Cartagena
}

\author{
The 13 Principles of the Cartagena Declaration \\ Os 13 Princípios da Declaração de Cartagena
}

Diana Cardenas ${ }^{*}$, Milena Puentes², Sonia Echeverri ${ }^{3}$, Angélica Pérez ${ }^{4}$, Lina López ${ }^{5}$, Charles Bermúdez ${ }^{6}$.

Recibido para publicación: 1 de septiembre de 2019. Aceptado para publicación: 1 de octubre 2019.

https://doi.org/10.35454/rncm.v2supl1.035

\section{Resumen}

La Declaración de Cartagena reconoce que el cuidado nutricional es un derecho humano. Para lograr que este derecho sea efectivo, la Declaración propone trece Principios, los cuales proporcionan un marco de referencia para promover el desarrollo del cuidado nutricional en el ámbito clínico que permita que todas las personas enfermas reciban terapia nutricional en condiciones de dignidad. La Declaración por medio de los principios, podrá servir como un instrumento para que se promuevan, a través de los gobiernos, la formulación de políticas y legislaciones en el campo de la nutrición clínica. También, se pretende que el marco general de principios ayude a crear conciencia acerca de la magnitud de este problema y a forjar redes de cooperación entre los países de la región. Por lo tanto, la Declaración de Cartagena debe considerarse un documento marco cuyos principios constituyen la base para promover el desarrollo de la atención nutricional en el campo clínico, y concientizar a las autoridades públicas, los organismos académicos y la industria farmacéutica.

En este artículo se presenta la definición, el contexto, el alcance, la perspectiva y algunos conceptos clave para cada uno de los Principios.

Palabras clave: Declaración de Cartagena, derechos humanos, principios.

\section{Summary}

The Cartagena Declaration recognizes that nutritional care is a human right. To make this human right effective, the Declaration provides a coherent framework of thirteen principles which provide a structure for promoting the development of nutritional care in the clinical setting, allowing all sick people to receive nutritional therapy in dignified conditions. The Declaration, through its principles, may also serve as an instrument to promote, through governments, the formulation of policies and laws in the field of clinical nutrition. The general framework of principles can contribute to raising awareness about the magnitude of this problem and to promote cooperation networks among Latin-American countries.

Thus, the Cartagena Declaration should be considered a framework document whose principles constitute the basis for promoting the development of nutritional care in the clinical field, and raising awareness among public authorities, academic bodies, and the pharmaceutical industry.

This article presents the definition, context, scope, perspective and some key concepts for each of the principles.

Keywords: Cartagena Declaration; Human rights; Principles.

\section{Resumo}

A Declaração de Cartagena reconhece que o cuidado nutricional é um direito humano. Para garantir que esse direito seja efetivo, a Declaração propõe treze princípios, que fornecem uma estrutura para promover o desenvolvimento dos cuidados nutricionais no ambiente clínico que permite que todas as pessoas doentes recebam terapia nutricional em condições dignas. A Declaração, por meio dos princípios, também pode servir como instrumento para promover, através dos governos, a formulação de políticas e leis no campo da nutrição clínica. Além disso, pretende-se que a estrutura geral de princípios ajude a aumentar a conscientização sobre a magnitude desse problema e criar redes de cooperação entre os países da região.

Portanto, a Declaração de Cartagena deve ser considerada um documento de estrutura cujos princípios constituem a base para promover o desenvolvimento do cuidado nutricional no campo clínico e conscientizar as autoridades públicas, os órgãos acadêmicos e a indústria farmacêutica.

Este artigo apresenta a definição, contexto, escopo, perspetiva e alguns conceitos-chave para cada um dos princípios

Palavras-chave: Declaração de Cartagena, direitos humanos, princípios.

\footnotetext{
Instituto de Investigación en Nutrición, Genética y Metabolismo, Facultad de Medicina, Universidad El Bosque, Bogotá, D.C., Colombia.

2 Liga Contra el Cáncer - Seccional Bogotá. Bogotá, D.C., Colombia. Tesorera ACNC 2017-2021.

3 Comité de Ética Hospitalaria y de Humanismo y Bioética. Fundación Santa Fe de Bogotá, Bogotá, D.C., Colombia. Vice-presidente FELANPE Región Centro 2019-2020.

*Correspondencia: Diana Cardenas dianacardenasbraz@gmail.com
}

\footnotetext{
4 Departamento de Nutrición y Bioquímica. Pontificia Universidad Javeriana. Bogotá, D.C., Colombia. Secretaria ejecutiva ACNC 2017-2021.

5 Grupo de Soporte Metabólico y Nutricional. Clínica Universitaria Colombia. Bogotá, D.C., Colombia. Vice-presidente ACNC 2017-2021.

6 Departamento de Cirugía. Clínica la Colina y Clínica del Country. Bogotá, D.C., Colombia. Presidente ACNC 2017-2021.
} 


\section{LOS PRINCIPIOS}

\section{PRINCIPIO \# 1}

\section{La alimentación en condiciones de dignidad de la persona enferma}

"Se reconoce el derecho al cuidado nutricional como un derecho humano emergente que se relaciona con el derecho a la salud y el derecho a la alimentación. Se destaca que la persona enferma debe ser alimentada en condiciones de dignidad, lo que implica reconocer durante el proceso de cuidado nutricional el valor intrínseco de cada ser humano, así como el respeto a la integridad, la diversidad de valores morales, sociales y culturales. El derecho al cuidado nutricional en el ámbito clínico comprende los aspectos cuantitativos, cualitativos y de aceptabilidad cultural ${ }^{(1)}$."

\section{Contexto}

En este principio se reconoce que el cuidado nutricional es un derecho humano y, por lo tanto, se debe alimentar a las personas enfermas en condiciones que respeten su dignidad. Debe considerarse el principio fundamental de la Declaración. Es el punto de partida, es la necesidad de responder a la problemática de la desnutrición asociada a la enfermedad y a la subalimentación de la persona enferma. Esta problemática es aún frecuente y poco se ha avanzado a pesar de que la ciencia de la nutrición clínica se ha desarrollado en los últimas décadas y que hoy disponemos de amplia evidencia que demuestra el impacto de la terapia nutricional, en el marco de un cuidado nutricional óptimo y oportuno, sobre el pronóstico y los desenlaces de los pacientes. Integrar el enfoque basado en derechos humanos en el campo de la nutrición clínica es una nueva perspectiva que brinda la oportunidad de comprometer distintas partes interesadas en una lucha común contra la malnutrición ${ }^{(2)}$.

\section{Alcance}

Reconocer el cuidado nutricional como un derecho humano y promover el respeto a la dignidad humana al alimentar a las personas enfermas tiene implicaciones sobre lo político, lo académico-científico lo ético y lo legal. Aunque la Declaración no es un instrumento jurídicamente vinculante, es decir que no obliga a las partes, sí las compromete en lo moral. Así las cosas, las sociedades científicas que han firmado la Declaración se han comprometido a reconocer y fomentar este derecho. Un primer paso es buscar que los gobiernos

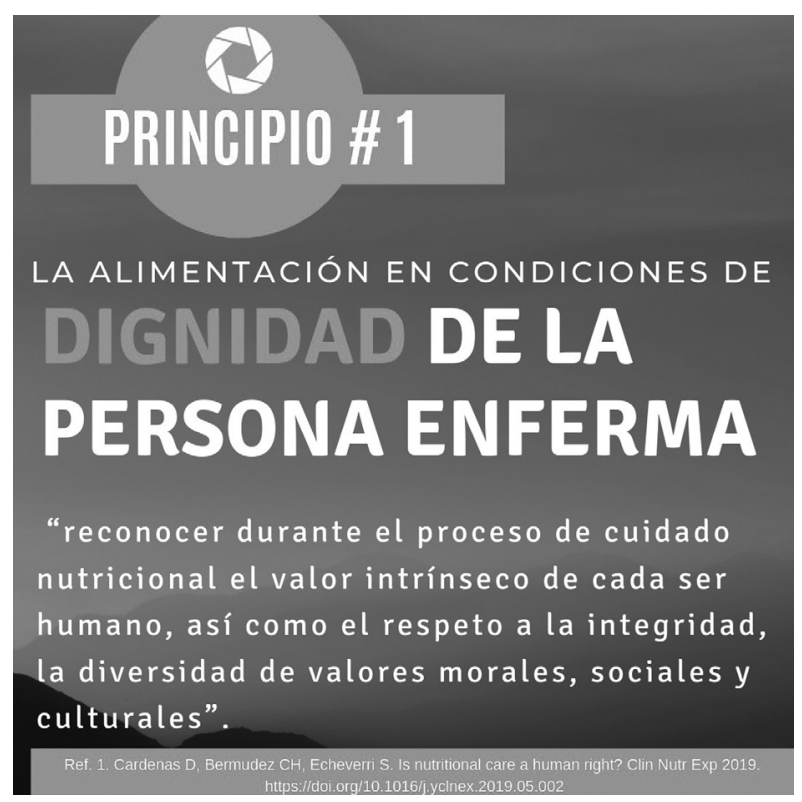

y los responsables políticos miren con interés la problemática de la malnutrición en el contexto clínico y promuevan políticas públicas y legislaciones en el tema. Desde lo académico, se debe promover la enseñanza y el reconocimiento de este derecho como un derecho humano emergente que se relaciona estrechamente con el derecho a la salud y a la alimentación. Desde la perspectiva ética es posible reconocer que el paciente en riesgo o con estado de desnutrición es una persona vulnerable debido al impacto sobre lo biológico, lo eco-

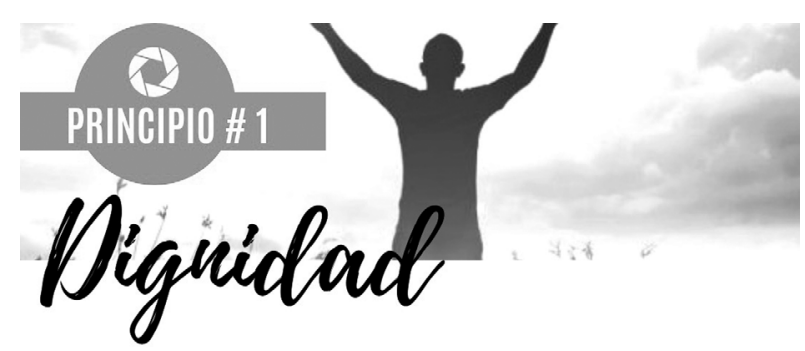

"Se reconoce el derecho al cuidado nutricional como un derecho humano emergente que se relaciona con el derecho a la salud y el derecho a la alimentación. Se destaca que la persona enferma debe ser alimentada en condiciones de dignidad, lo que implica reconocer durante el proceso de cuidado nutricional el valor intrínseco de cada ser humano, así como el respeto a la integridad, la diversidad de valores morales, sociales y culturales. El derecho al cuidado nutricional en el ámbito clínico comprende los aspectos cuantitativos, cualitativos y de aceptabilidad cultural."

\section{Declaraciṓn de Gartagena}

\footnotetext{
** Imágenes diseñadas por Milena Puentes en el marco de la divulgación de la Declaración de Cartagena.
} 
nómico y lo social. Además, nos responsabiliza frente a esta problemática y nos obliga a actuar por un cuidado nutricional para todas las personas.

\section{Perspectiva}

La firma de la Declaración de Cartagena, el 3 de mayo de 2019, es el punto de partida de acciones comunes en Latino América, pero sin perder de vista el enfoque global de las acciones ${ }^{(1)}$. El programa de implementación de la Declaración busca en primera instancia brindar las herramientas necesarias para poder traducir los principios en acciones. Es decir, la Declaración nos indica "qué" se debe hacer y las herramientas indicarán "cómo" se debe hacer. El Primer Principio estará presente directa $o$ indirectamente en cada una de las herramientas.

\section{Concepto clave}

\section{La noción de dignidad}

La dignidad se refiere al valor intrínseco de cada ser humano por el simple hecho de serlo. Según Emmanuel Kant, la dignidad implica el hecho de que la persona nunca debe ser tratada como un medio, sino como un fin en sí misma. En el cuidado nutricional la noción de dignidad implica, como lo dice el primer principio, "reconocer durante el proceso de cuidado nutricional el valor intrínseco de cada ser humano, así como el respeto a la integridad, la diversidad de valores morales, sociales y culturales".

\section{PRINCIPIO \# 2}

\section{El cuidado nutricional es un proceso}

"El cuidado nutricional forma parte de la atención integral del paciente, y, por tanto, debe ser un componente inherente a su cuidado. Se concibe como un proceso continuo que consta de diversas etapas, las cuales se pueden resumir en: 1. Detectar, 2. Nutrir y 3. Vigilar.

En consecuencia, las instituciones de salud deberán promover el desarrollo del modelo de atención nutricional basado en detectar, nutrir, vigilar ${ }^{(1)}$.

\section{Contexto}

En el Principio \# 2 se reconoce que el cuidado nutricional es un proceso y está íntimamente ligado al \# 1 . En el Principio \# 1 de la Declaración de Cartagena se estipula que el paciente debe ser alimentado en condiciones que garanticen el respeto de la dignidad humana.

¿Cómo se logra? Es posible garantizar el respeto de la dignidad humana si el paciente es alimentado teniendo en cuenta los aspectos culturales, simbólicos y afectivos o emocionales de la nutrición, además de reconocer los riesgos, los beneficios y los límites de la terapia nutricional. $\mathrm{Al}$ igual que toda terapia médica, la terapia nutricional debe tener una indicación y debe ser administrada con el consentimiento del paciente. Para garantizar la administración de una adecuada terapia nutricional esta debe concebirse en el marco de un proceso continuo que inicia con la identificación del riesgo nutricional. 
paciente (Principio \# 3). El Principio \# 2 reconoce que toda persona que consulte un servicio médico, en cualquier nivel de atención, tiene derecho de beneficiarse del proceso de cuidado nutricional. Es decir, que una vez se ha identificado el riesgo o se ha hecho el diagnóstico del estado nutricional, la persona debe ser alimentada teniendo en cuenta los beneficios que puede tener según la indicación médica precisa y solo después de su consentimiento. El Principio \# 2 también tiene implicaciones sobre los aspectos académicos pues se debe asegurar que los profesionales de la salud adquieran las competencias necesarias para realizar las tres etapas del cuidado nutricional.

Así las cosas, las sociedades científicas que han firmado la Declaración se han comprometido a reconocer y promocionar el cuidado nutricional como un proceso, y para ello un primer paso es buscar que los gobiernos y las instituciones miren con interés la problemática de la malnutrición y promuevan la implementación del modelo de cuidado nutricional basado en tres etapas y con un enfoque interdisciplinario. Desde lo académico se debe promover la enseñanza de las distintas etapas del cuidado nutricional.

\section{Perspectiva}

El Principio \# 2 es fundamental para el desarrollo de la nutrición clínica y para garantizar el respeto del derecho al cuidado nutricional. El programa de implementación de la Declaración tendrá herramientas necesarias para definir que los profesionales y las instituciones pongan en marcha el modelo de cuidado nutricional. Las tres etapas buscan que el cuidado nutricional se brinde con seguridad, oportunidad, eficiencia, eficacia y efectividad.

\section{Conceptos clave}

\section{Detectar}

La identificación del riesgo nutricional realizado por medio del tamizaje es la primera etapa, lo cual conlleva, en la siguiente etapa, si el paciente está en riesgo, a la realización del diagnóstico completo del estado nutricional permitiendo establecer la indicación médica de terapia nutricional y la realización del plan nutricional. El tamizaje nutricional debe ser sistemático para las personas enfermas en cualquier nivel de atención en salud. Todo paciente con riesgo nutricional deberá beneficiarse de un diagnóstico nutricional completo.

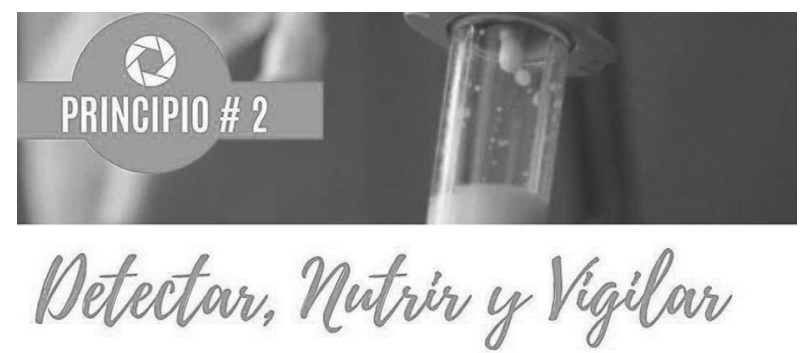

"Reconocer el cuidado nutricional como un proceso tiene implicaciones principalmente sobre la organización de la atención al paciente.

Las actividades deben organizarse y estandarizarse para que se realice la detección, la terapia nutricional y el monitoreo del cuidado nutricional según las condiciones y las particularidades de cada sistema de salud o de cada institución."

El diagnóstico nutricional permite identificar las alteraciones nutricionales, las cuales pueden ser: a. Malnutrición (sinónimo de desnutrición), b. Sobrepeso y obesidad, c. Anormalidades de micronutrientes. La malnutrición o desnutrición se define como la condición que resulta de la falta de ingesta, de la absorción nutricional alterada, de pérdidas de nutrientes incrementadas que conlleva a cambios de la composición corporal (disminución de la masa libre de grasa) y de la masa celular corporal lo que produce la disminución de las funciones mentales, físicas y al deterioro del resultado clínico. La desnutrición puede ser el resultado del ayuno/inanición, la enfermedad o la edad avanzada (i.e. > 70 años). Cada una se puede presentar de manera aislada o de manera combinada.

La malnutrición se puede presentar como: a. Malnutrición sin enfermedad, b. Malnutrición asociada a la enfermedad con inflamación (aguda o crónica), c. Malnutrición asociada a la enfermedad sin inflamación.

Se hace hincapié en que los criterios diagnósticos de malnutrición establecidos por consenso deberían ser evaluados en el contexto Latinoamericano, teniendo en cuenta las características fenotípicas de la población y la situación socio económica, entre otras. La detección del riesgo nutricional debe ser prioridad en todos los niveles de atención en salud.

\section{Nutrir}

El plan nutricional incluye la terapia nutricional (o terapia médica nutricional), es decir, con alimentos 
naturales de administración ordinaria y con nutrientes artificiales administrados por medio de suplementos, nutrición enteral y parenteral. Se considera que la terapia nutricional es una intervención médica, que requiere una indicación médico-nutricional, que tiene un objetivo de tratamiento específico y que necesita el consentimiento informado del paciente. Como toda terapia, la nutrición también tiene efectos secundarios, riesgos y beneficios. Se tienen en cuenta las dimensiones biológicas (cuantitativa y cualitativa), simbólica, afectiva y cultural asociada a la alimentación, incluso si se trata de terapia nutricional artificial.
Vigilar

La terapia nutricional se debe monitorear y documentar. El monitoreo busca verificar que se cumplan las distintas dimensiones de la terapia nutricional, así como prevenir los efectos secundarios. La documentación sirve para seguir y evaluar la continuidad de la terapia de cada paciente y garantizar la calidad. Es importante poder iniciar un proceso de gestión del riesgo y "asegurabilidad" en el ámbito clínico.

\section{PRINCIPIO \# 3}

\section{El empoderamiento de los pacientes como acción necesaria para mejorar el cuidado nutricional}

"El acto de empoderar a los pacientes y sus familias en la lucha contra la malnutrición implica darles la capacidad para pensar de manera crítica sobre la malnutrición y sus respectivas consecuencias negativas, permitiéndole al mismo tiempo tomar decisiones autónomas e informadas, como exigir atención nutricional y cumplir el tratamiento nutricional sugerido ${ }^{(1)}$."

\section{Contexto}

El Principio \# 3 de la Declaración de Cartagena reconoce el rol central del paciente en el proceso del cuidado nutricional descrito en el Principio \# 2. El Tercer Principio se enmarca en la necesidad de pasar de un modelo de relación paternalista del paciente con el médico o sistema de salud a un modelo donde las decisiones sean compartidas. Un modelo de cuidado nutricional inspirado en el empoderamiento busca potenciar las capacidades propias del paciente para manejar la nutrición en enfermedades agudas o crónicas y su capacidad para tomar el control de su vida. El empoderamiento implica que el paciente y su red de apoyo, se comprometen con la terapia nutricional pasando del simple hecho de recibir la información de manera pasiva a la implicación activa en las decisiones. También implica que el profesional del cuidado nutricional debe transmitir ciertas informaciones para que el paciente y su red tenga capacidad de actuar en total libertad.

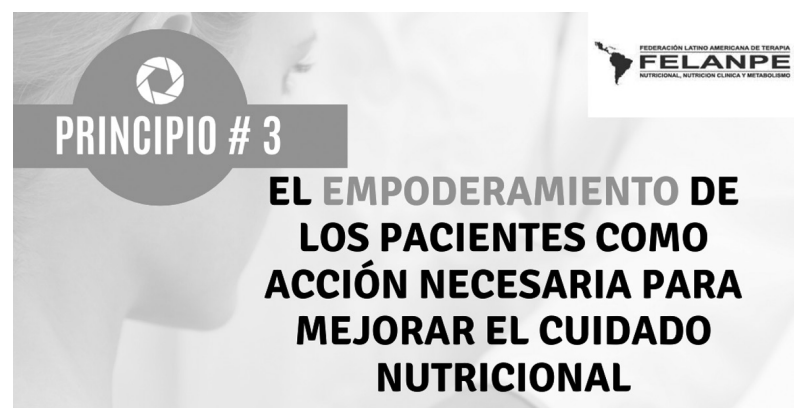

"El acto de empoderar a los pacientes y sus familias en la lucha contra la malnutrición implica darles la capacidad para pensar de manera crítica sobre la malnutrición y sus respectivas consecuencias negativas, permitiéndole al mismo tiempo tomar decisiones autónomas e informadas, como exigir atención nutricional y cumplir el tratamiento nutricional sugerido."

\section{Alcance}

Reconocer que el empoderamiento de los pacientes es una acción necesaria para mejorar el cuidado nutricional y para promover el respeto de la dignidad humana tiene implicaciones sobre los aspectos organizacionales, lo académico-científico y lo ético. Desde el punto de vista organizacional, las etapas del modelo de cuidado nutricional "Detectar, nutrir y vigilar" deben tener en cuenta acciones de educación y sensibilización de los pacientes. Los profesionales de la salud deben adquirir competencias para educar y transmitir la información al paciente para poder tomar las decisiones de manera conjunta. Desde el punto de vista de la ética, el empoderamiento implica reconocer el principio de autonomía del paciente (respeto a la capacidad de decidir de las personas, y el 
derecho a que se respete su voluntad), la responsabilidad de los profesionales en nutrición clínica de alimentar a la persona enferma y el principio de equidad en salud.

Las sociedades científicas que han firmado la Declaración se han comprometido a reconocer y promocionar el cuidado nutricional, y a reconocer la importancia de empoderar al paciente en la toma de decisiones durante este proceso.

Para ello, un primer paso es buscar que los gobiernos y las instituciones miren con interés la problemática de la malnutrición y promuevan la implementación del modelo de cuidado nutricional basado en tres etapas, con un enfoque interdisciplinario e involucrando el empoderamiento del paciente. Desde lo académico se debe promover la enseñanza de las distintas etapas del cuidado nutricional y las técnicas de educación terapéutica y empoderamiento.

\section{Perspectiva}

El Principio \# 3 es fundamental para el desarrollo de la nutrición clínica y para garantizar el respeto del derecho al cuidado nutricional. El programa de implementación de la Declaración tendrá herramientas necesarias para que los profesionales y las instituciones pongan en marcha este principio. Se debería sensibilizar a las distintas asociaciones de pacientes acerca de la importancia del cuidado nutricional en cualquier enfermedad.

\section{Conceptos clave}

El empoderamiento se define como un proceso y un resultado. El primero se basa en que, al aumentar la

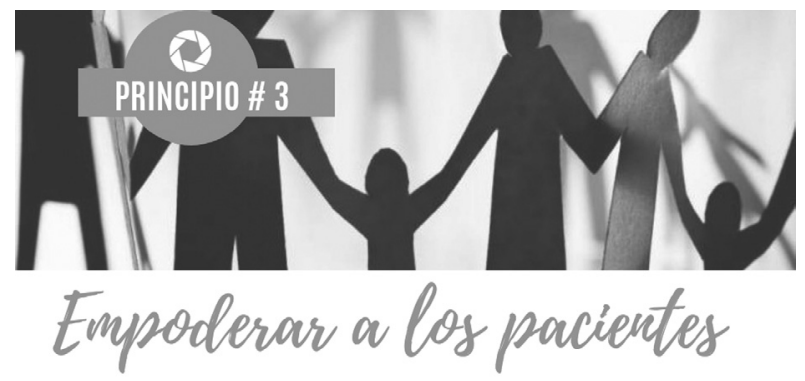

"El empoderamiento se define como un proceso y un resultado. El primero se basa en que, al aumentar la educación se mejora la capacidad de pensar en forma crítica y de actuar de manera autónoma, mientras que el segundo (resultado), se logra mediante el sentido de autoeficacia,el resultado del proceso."

TFELANPE

Declaración de Gartagena

educación se mejora la capacidad de pensar en forma crítica y de actuar de manera autónoma, mientras que el segundo (resultado), se logra mediante el sentido de autoeficacia.

El empoderamiento se realiza a través de la educación y la educación implica libertad. En el cuidado nutricional, empoderar a los pacientes significa ofrecerles la oportunidad de ser parte del proceso y tratamiento nutricional; en consecuencia, no solo se busca obtener una voz, sino también compartir conocimientos y responsabilidades con ellos y con la familia. El empoderamiento busca aumentar la libertad y autonomía del paciente (la capacidad de tomar decisiones informadas) sobre el papel de la malnutrición y la terapia nutricional en las diferentes fases de tratamiento.

\section{PRINCIPIO \# 4}

\section{El enfoque interdisciplinario del cuidado nutricional}

"Este enfoque implica la integración equitativa de las diversas disciplinas relacionadas con la actividad nutricional. La evidencia científica muestra las ventajas de este enfoque en términos de costo-efectividad, seguridad, eficiencia y eficacia ${ }^{(1)}$.”

\section{Contexto}

El Principio \# 4 de la Declaración de Cartagena reconoce la importancia de la interdisciplinariedad en la

práctica del cuidado nutricional. El enfoque interdisciplinario ha sido esencial para poner en práctica los adelantos médicos y científicos que llevaron al desarrollo de la terapia nutricional en las últimas décadas. A medida que se desarrolló la terapia nutricional, se crearon equipos multidisciplinarios de terapia nutricional, que fueron migrando a interdisciplinarios, para optimizar la efectividad y la seguridad de esta terapia. Se ha demostrado que el impacto de la estandarización y el cuidado nutricional a través de grupos interdisciplinarios mejoran los resultados y la seguridad del paciente, y tienen un impacto económico positivo en las instituciones de salud. Sin embargo, muchos hospitales no tienen grupos de terapia nutricional. 


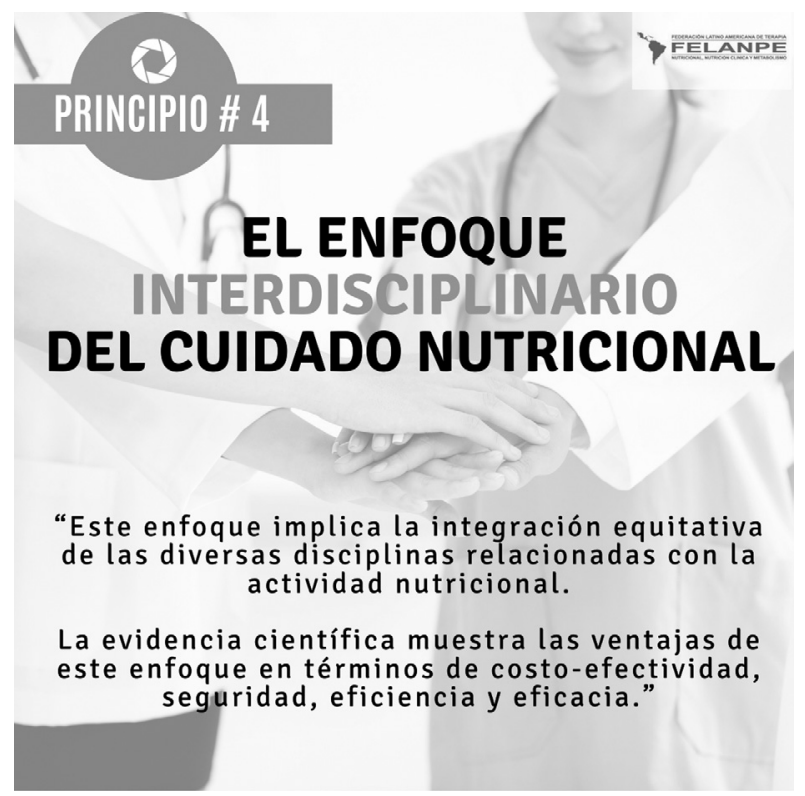

\section{Alcance}

Reconocer la importancia del enfoque interdisciplinario en el cuidado nutricional tiene implicaciones principalmente académicas, pero también sobre los aspectos organizacionales. Se recomienda administrar la terapia nutricional en el marco de grupos de terapia nutricional donde participen como mínimo, profesionales de la nutrición, enfermería, medicina, farmacia. Además, se aconseja la inclusión de otras disciplinas como la fonoaudiología, la terapia ocupacional, la fisioterapia, la rehabilitación, el trabajo social y la psicología que incrementan la eficacia de la terapia nutricional. Desde lo académico, no solo se debe formar a los profesionales de estas disciplinas en el campo de la nutrición clínica, sino definir las competencias específicas disciplinares.

Las sociedades científicas que han firmado la Declaración se han comprometido a reconocer la importancia del enfoque interdisciplinario en el cuidado nutricional. Desde lo académico se debe promover educación de los profesionales que integran los equipos interdisciplinarios de terapia nutricional

\section{Perspectiva}

Se deberá promocionar la creación de los equipos interdisciplinarios de terapia nutricional y la acredi- tación de los equipos que están en funcionamiento, a través de la medición de sus resultados. En la Interdisciplinariedad las distintas disciplinas interactúan respetando cada una el área de trabajo específico de la otra. Hay una cohesión de saberes, donde se aporta conocimiento desde la perspectiva disciplinar, se comparte responsabilidad, pero se mantiene la competencia de cada disciplina. Por ello, se hace necesario reconocer los límites y las competencias de las distintas disciplinas que interactúan en el cuidado nutricional. En el programa de implementación se desarrollarán herramientas que permitirán desarrollar el enfoque interdisciplinario.

\section{Conceptos clave}

La interdisciplinariedad según la Real Academia de la Lengua se define como una actividad "Que se realiza con la cooperación de varias disciplinas". La multidisciplinariedad y la transdisciplinariedad son conceptos cercanos y complementarios. En la Interdisciplinariedad las distintas disciplinas interactúan respetando cada una el área de trabajo específico de la otra.

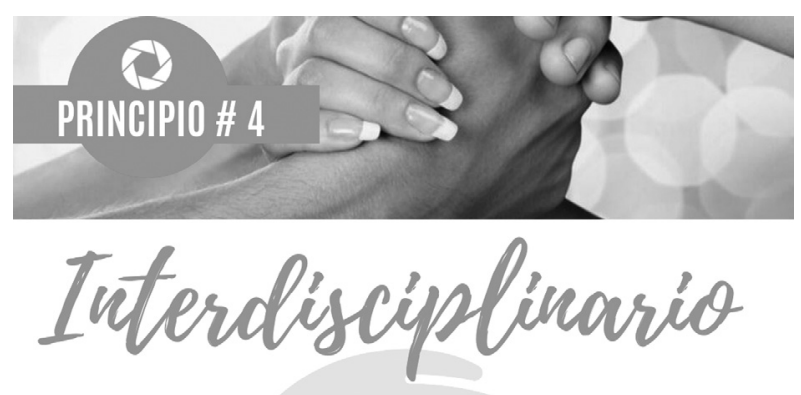

Según la Real Academia de la Lengua se define como una actividad "Que se realiza con la cooperación de varias disciplinas".

La multidisciplinariedad y la transdisciplinariedad son conceptos cercanos y complementarios. En la Interdisciplinariedad las distintas disciplinas interactúan respetando cada una el área de trabajo especifico de la otra.

FELANPE Declaración de Gartagena 


\section{PRINCIPIO \# 5}

\section{Principios y valores éticos en el cuidado nutricional}

"Se reconoce que los pacientes en riesgo o en estado de malnutrición son un grupo considerado vulnerable desde el punto de vista ético. La vulnerabilidad es una dimensión ineludible de los seres humanos y la configuración de las relaciones sociales. Considerar la vulnerabilidad del paciente desnutrido implica reconocer que los individuos pueden carecer en algún momento de la capacidad y los medios para alimentarse por sí mismos y, por lo tanto, es preciso que esta necesidad la atiendan profesionales en nutrición clínica ${ }^{(1)}$."

\section{Contexto}

En el Principio \# 5 de la Declaración de Cartagena se reconoce la necesidad de fundamentar la práctica del cuidado nutricional en principios y valores éticos. La terapia nutricional se considera un gran avance científico y tecnológico que ha permitido alimentar a la persona enferma y mejorar los desenlaces clínicos, la calidad de vida e impactar en los costos de la salud. Se reconoce que con estos adelantos surgen cuestiones bioéticas que pueden tener repercusiones en los individuos, las familias y grupos o comunidades. El Principio \# 5 propone que dichas cuestiones sean analizadas en el marco de los principios establecidos en la Declaración Universal de Bioética y Derechos Humanos de la UNESCO $(\mathrm{DUBDH})$ en especial los principios universales de igualdad, justicia y equidad, no discriminación y no estigmatización, no maleficencia, autonomía, beneficencia y el respeto de la vulnerabilidad humana y la integridad personal ${ }^{(3)}$. Además, este principio reconoce que el respeto de la diversidad cultural y del pluralismo es fundamental en la realización del cuidado nutricional y en el debate de los cuestionamientos éticos.

\section{Alcance}

El Principio \# 5 establece la necesidad de darle un enfoque ético al cuidado nutricional. Un aspecto fundamental de este enfoque es que se reconoce que los pacientes en riesgo o en estado de malnutrición son un grupo que debe considerarse vulnerable. Esta vulnerabilidad se explica por el impacto de la malnutrición en los aspectos biológicos, psicológicos y sociales (con el riesgo de perder la vida y la posibilidad de perder la autonomía) y por que la malnutrición es un síndrome

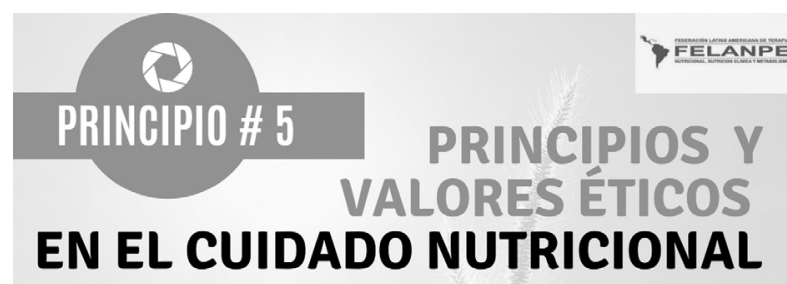

"Se reconoce que los pacientes en riesgo o en estado de malnutrición son un grupo considerado vulnerable desde el punto de vista ético. La vulnerabilidad es una dimensión ineludible de los seres humanos y la configuración de las relaciones sociales.

Considerar la vulnerabilidad del paciente desnutrido implica reconocer que los individuos pueden carecer en algún momento de la capacidad y los medios para alimentarse por símismos y, por lo tanto, es preciso que esta necesidad la atiendan profesionales en nutrición clínica."

que con frecuencia es ignorado en el contexto clínico. La vulnerabilidad es una dimensión ineludible de los seres humanos y la configuración de las relaciones sociales. Considerar la vulnerabilidad del paciente desnutrido implica reconocer que los individuos pueden carecer en algún momento de la capacidad y los medios para alimentarse por sí mismos y, por lo tanto, es preciso que esta necesidad la atiendan profesionales en nutrición clínica.

Las sociedades científicas que han firmado la Declaración se han comprometido a reconocer la importancia del enfoque ético en el cuidado nutricional. Se espera que se promueva la enseñanza de la ética, las discusiones y los espacios de debate ético en torno al cuidado nutricional.

\section{Perspectiva}

El cuidado nutricional como derecho humano implica que toda persona con o en riesgo de desnutrición, debe tener acceso al cuidado nutricional y en particular a la terapia nutricional óptima y oportuna. Este derecho debe ejercerse con un fundamento ético y con profesionalismo. El fundamento ético establece los valores y principios necesarios para la práctica del cuidado nutricional. Estos principios tendrán un impacto en las acciones y decisiones que se tomen al alimentar a la persona enferma. Se busca que dichas acciones respeten la autonomía de la persona, tengan en cuenta los beneficios 


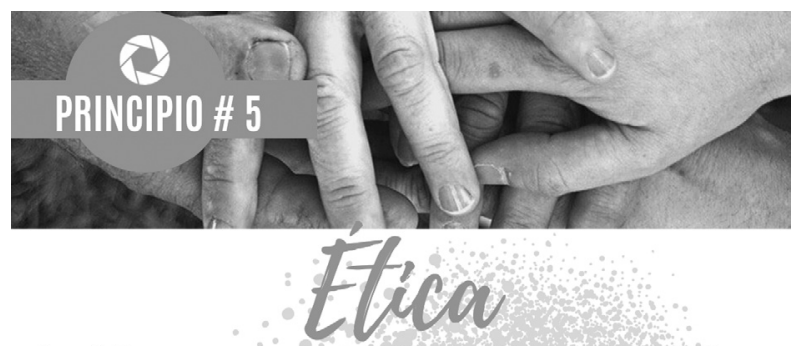

La ética es una rama de la filosofía que tiene como objetivo realizar un análisis intelectual de la dimensión moral humana en toda su complejidad.

La ética se ocupa de los principios que nos permiten tomar decisiones sobre lo que es correcto e incorrecto. En otras palabras, la ética es el estudio de lo que es moralmente correcto y de lo que no es.

FELANPE

\section{Declaraciōn de Gartagena}

y riesgos posibles y se limiten las acciones fútiles. Este principio también tiene una dimensión deontológica ya que establece que se deberían promover el profesionalismo, la honestidad, la integridad y la transparencia en la adopción de decisiones, en particular en las declaraciones de todos los conflictos de interés y el aprovechamiento compartido de conocimientos de acuerdo con lo establecido en el artículo 18 de la DUBDH.
El programa de implementación de la Declaración de Cartagena desarrollará herramientas que permitirán el desarrollo de programas de formación en ética del cuidado nutricional. Estas herramientas permitirán que el enfoque ético sea tenido en cuenta en el cuidado nutricional y será esencial para promover el respeto de este derecho humano.

\section{Conceptos clave}

\section{Ética}

La ética es una rama de la filosofía que tiene como objetivo realizar un análisis intelectual de la dimensión moral humana en toda su complejidad. La ética se ocupa de los principios que nos permiten tomar decisiones sobre lo que es correcto e incorrecto. En otras palabras, la ética es el estudio de lo que es moralmente correcto y de lo que no es.

Un dilema ético es aquella situación en la que las obligaciones morales exigen o parecen exigir que una persona adopte una o más acciones alternativas pero incompatibles, de modo que la persona no puede realizar todas las acciones requeridas. En esas situaciones, existe un conflicto o tensión entre el respeto de dos o más principios que hace que sea difícil decidir qué se debe hacer. Las decisiones relacionadas con acciones fútiles en general conllevan dilemas éticos.

\section{PRINCIPIO \# 6}

\section{La integración de la atención en salud basada en el valor (aspectos económicos)}

"Se deberían integrar los aspectos económicos en el ejercicio, la evaluación y la investigación en nutrición clínica. Se propone integrar la atención en salud basada en el valor del cuidado nutricional. Bajo este enfoque, se busca reorientar los servicios de salud para que logren mejorar la satisfacción de las necesidades en salud de las personas, en particular del cuidado nutricional mientras mantienen una relación óptima con los costos y los resultados. Generar valor implica un énfasis en lograr resultados en salud tanto para los pacientes como para las organizaciones y la sociedad manteniendo una relación óptima con los costos ${ }^{(1)}$."

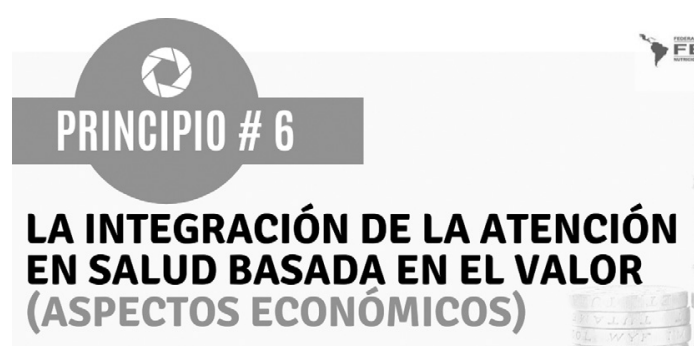

"Se deberían integrar los aspectos económicos en el ejercicio, la evaluación y la investigación en nutrición clínica. Se propone integrar la atención en salud basada en el valor del cuidado nutricional. Bajo este enfoque, se busca reorientar los servicios de salud para que logren mejorar la satisfacción de las necesidades en salud de las personas, en particular del cuidado nutricional mientras mantienen una relación óptima con los costos y los resultados.

Generar valor implica un énfasis en lograr resultados en salud tanto para los pacientes como para las organizaciones y la sociedad manteniendo una relación óptima con los costos." 


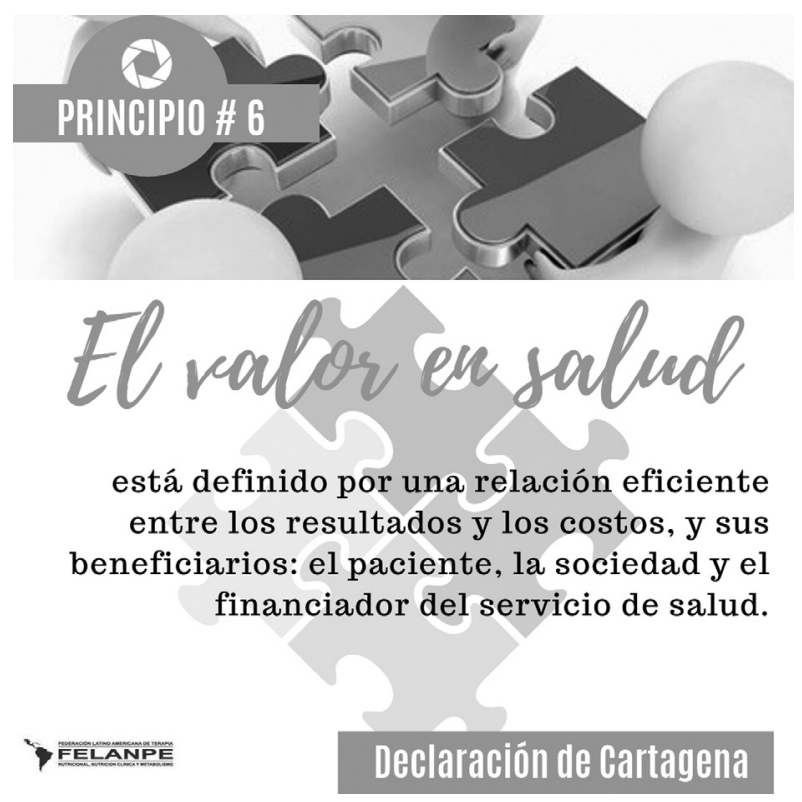

\section{Contexto}

En el Principio \# 6 de la Declaración de Cartagena se reconoce la necesidad de integrar los aspectos económicos principalmente en el ejercicio de la nutrición clínica. Surge de la necesidad de integrar el cuidado nutricional en sistemas de salud garantizando la eficiencia. Es decir, los sistemas y las organizaciones de salud deben poder garantizar la terapia nutricional, buscando una atención en salud con los mejores resultados posibles y manteniendo una relación adecuada con los costos.

\section{Alcance}

El Principio \# 6 establece la necesidad de dar un enfoque basado en el valor e integrar los aspectos econó- micos al cuidado nutricional. Un aspecto fundamental de este enfoque es que se reconozca la necesidad de garantizar en todos los sistemas de salud los procesos regulatorios adaptados y el reembolso de los productos nutricionales (suplementos, nutrición enteral y parenteral), las consultas de especialistas y que se integren los cuatro pasos del cuidado nutricional (detectar, diagnosticar, nutrir y vigilar).

Las sociedades científicas que han firmado la Declaración se han comprometido a reconocer la importancia de la integración de la atención en salud basada en el valor (aspectos económicos).

\section{Perspectiva}

La persona enferma tiene el derecho a recibir atención nutricional segura y de calidad, con personal calificado y procurando costo efectividad, basados en la evidencia científica. Se deberían asignar recursos según las políticas públicas enfocadas en la promoción, prevención e intervención nutricional que resulten en mejorar la calidad de vida de los pacientes. Para esto es fundamental que se implementen programas de calidad que integren elementos de la economía de la salud: costo minimización, costo eficacia, costo beneficio, costo efectividad y costo utilidad

\section{Conceptos clave}

El valor en salud está definido por una relación eficiente entre los resultados y los costos, y sus beneficiarios: el paciente, la sociedad y el financiador del servicio de salud.

\section{PRINCIPIO \# 7}

\section{La investigación en nutrición clínica es un pilar para el cumplimiento del derecho al cuidado nutricional y la lucha contra la malnutrición}

"Se debería impulsar el desarrollo de la investigación en nutrición clínica bajo un nuevo paradigma, el cual consiste en una visión de la nutrición clínica que considere que la persona enferma necesita, más allá de comida y nutrientes, el abordaje del metabolismo en el contexto particular de la enfermedad y el mejor conocimiento de su estado metabólico y nutricional. Para ello, es necesario desarrollar la investigación para entender los mecanismos biológico-moleculares asociados a los estados metabólicos de las personas enfermas ${ }^{(1)}$.”

\section{Contexto}

En el Principio \# 7 de la Declaración de Cartagena se reconoce la necesidad de impulsar el desarrollo de la investigación en nutrición clínica bajo un nuevo paradigma. Surge de la necesidad de entender que la terapia nutricional no implica simplemente la administración de nutrientes para suplir unos requerimientos. La admi- 


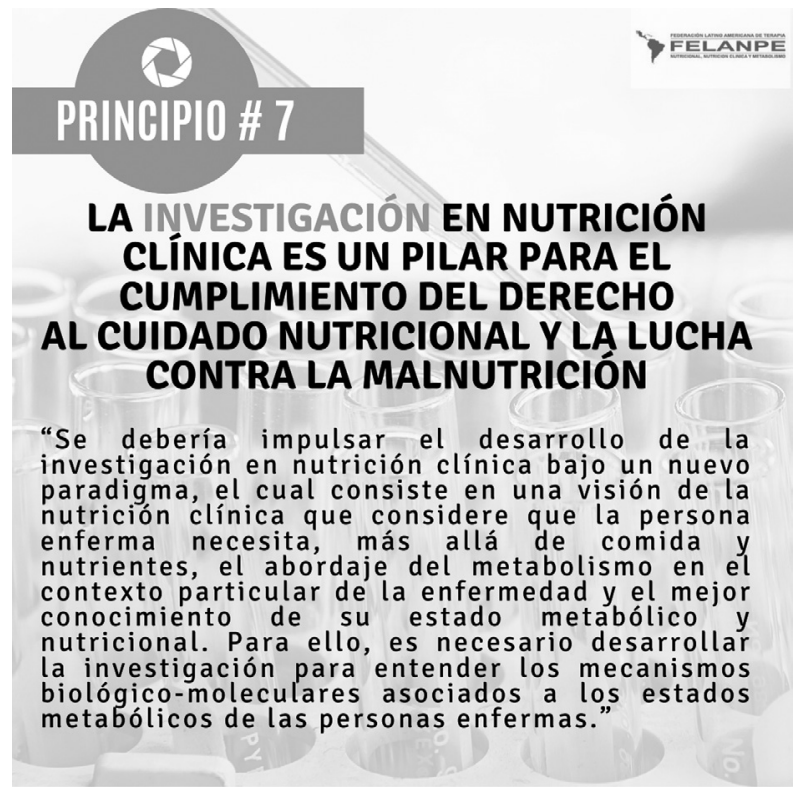

nistración de la terapia nutricional implica también entender que la persona enferma presenta situaciones y alteraciones metabólicas específicas que podrían considerarse adaptativas de la lesión o la enfermedad. Por ello, la terapia nutricional debe ajustarse a la situación metabólica de cada paciente.

\section{Alcance}

El Principio \# 7 establece la necesidad de impulsar el desarrollo de la investigación en nutrición clínica. Se trata de promover la investigación de los mecanismos y aspectos fisiológicos y moleculares de las adaptaciones metabólicas del paciente con lesión o enfermo. Un aspecto fundamental de este enfoque es la necesidad de promover la investigación y la innovación en productos de terapia nutricional que permitan la administración de nutrientes de manera adaptada a cada situación. También es necesario desarrollar la investigación para conocer los mecanismos fisiológicos moleculares propios a las situaciones como sarcopenia, caquexia y carencias en micronutrientes.

\section{Perspectiva}

Las sociedades científicas que han firmado la Declaración se han comprometido a promover la investigación. Para ello se deberá exigir a las autoridades gubernamentales, a las instituciones académicas y a las compañías farmacéuticas mayor inversión y apoyo a la investigación en nutrición clínica. La problemática de la desnutrición asociada a la enfermedad y su impacto en los sistemas de salud deberá tener más visibilidad para que la investigación en este campo pueda ser una prioridad. Se reconoce que los intereses y el bienestar de la persona deberían tener prioridad con respecto al interés exclusivo de la ciencia o la sociedad (industria farmacéutica, empresas, etc.).

El programa de implementación de la Declaración de Cartagena desarrollará herramientas que permitirá el cumplimento de los siguientes objetivos: a) investigar sobre los problemas de nutrición clínica relevantes bajo los estándares científicos de calidad, la medicina basada en la evidencia y respetando los principios de la bioética; b) desarrollar líneas de investigación pertinentes en el contexto regional (latinoamericano); c) evaluar los adelantos de la ciencia y la tecnología que surgen en el campo de la nutrición clínica; d) apoyar la formulación de recomendaciones, guías y consensos de prácticas clínicas basados en la evidencia científica; e) fomentar el debate, la educación y la sensibilización del público sobre la nutrición clínica y el problema de la malnutrición, así como la participación al respecto del derecho a la alimentación en este ámbito.

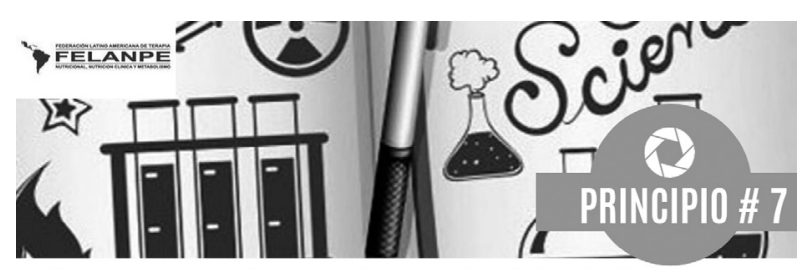

El programa de implementación de la Declaración de Cartagena desarrollará herramientas que permitirá el cumplimento de los siguientes objetivos:

a) investigar sobre los problemas de nutrición clínica b) desarrollar líneas de investigación pertinentes en el contexto regional (latinoamericano)

c) evaluar los adelantos de la ciencia y la tecnología que surgen en el campo de la nutrición clínica d) apoyar la formulación de recomendaciones, guías y consensos de prácticas clínicas basados en la evidencia científica

e) fomentar el debate, la educación y la sensibilización del público sobre la nutrición clínica y el problema de la malnutrición,

Declaración de Gartagena 


\section{PRINCIPIO \# 8}

\section{La educación en nutrición clínica es un eje fundamental para el cumplimiento del derecho al cuidado nutricional y la lucha contra la malnutrición}

"Se deberá crear, promover y apoyar, al nivel que corresponda, y bajo el nuevo paradigma la educación en nutrición clínica. En el pregrado: fomentar la enseñanza de la nutrición clínica en las carreras de la salud (medicina, nutrición, enfermería, farmacia, etc.). En el posgrado de medicina y otras carreras de la salud: reconocer la nutrición clínica como especialidad clínica y no como subespecialidad o formación complementaria ${ }^{(1)}$."

\section{Contexto}

En el Principio \# 8 de la Declaración de Cartagena se reconoce la necesidad de promover la educación en nutrición clínica. Este Principio surge frente a la falta de educación en nutrición clínica en las formaciones de pregrado y de posgrado de los profesionales de la salud, médicos, enfermeras y nutricionistas, entre otros. A pesar de la evidencia de que los médicos están dispuestos, entienden la importancia del cuidado nutricional, y se consideran fuentes creíbles de información sobre la nutrición, estos profesionales no realizan cuidado nutricional y citan como barrera la falta de conocimiento y la formación insuficiente. Estos datos se alinean con la evidencia de brechas

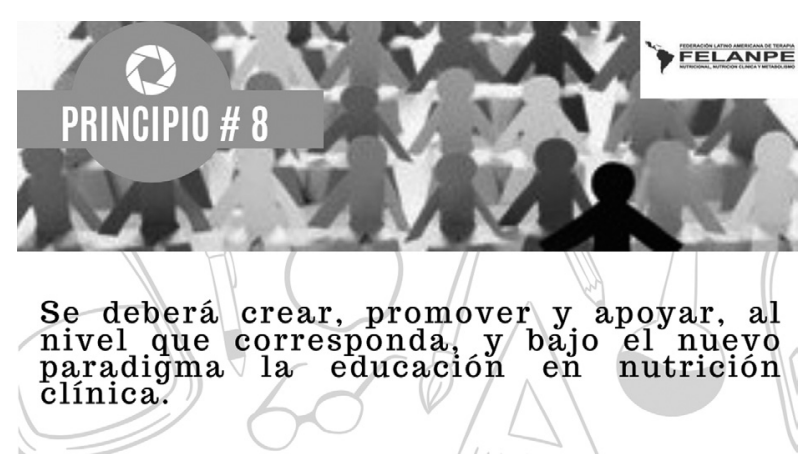

En el pregrado: fomentar la enseñanza de la nutrición clínica en las carreras de la salud (medicina, nutrición, enfermería, farmacia, etc.).

En el posgrado de medicina y otras carreras de la salud: reconocer la nutrición clínica como especialidad clínica y no como subespecialidad o formación complementaria.

Declaración de Gartagena

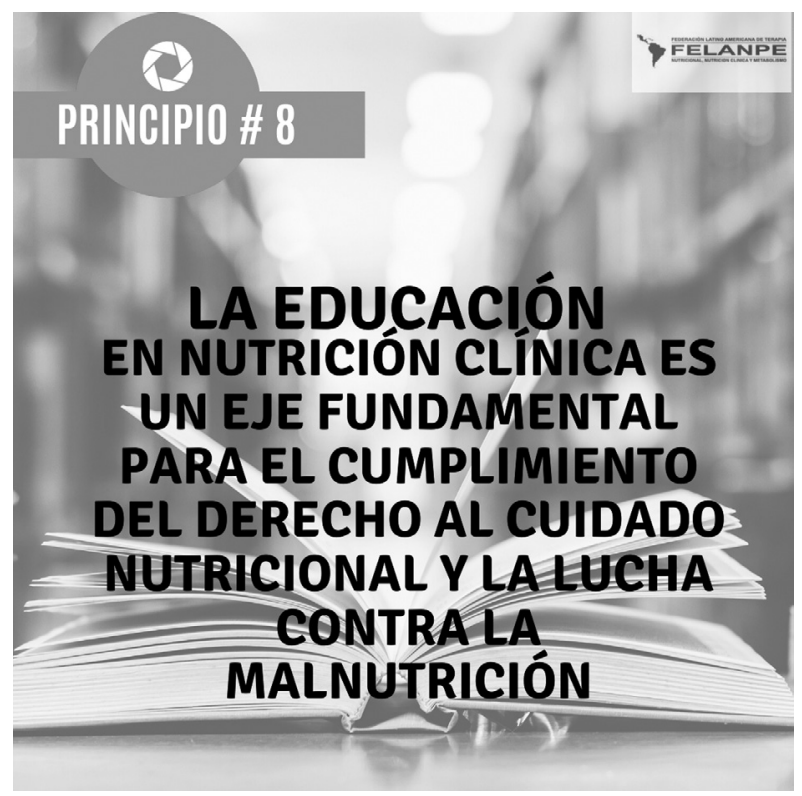

persistentes en la educación y formación en nutrición médica en los Estados Unidos y Europa.

\section{Alcance}

El Principio \# 8 establece la necesidad de impulsar la educación en nutrición clínica. Se trata de promover la introducción de un currículo básico en nutrición en las facultades de las carreras de la salud (medicina, nutrición, enfermería, farmacia, etc.). En el posgrado de medicina y otras carreras de la salud: reconocer la nutrición clínica como especialidad clínica y no como subespecialidad o formación complementaria.

\section{Perspectiva}

Las sociedades científicas que han firmado la Declaración se han comprometido a promover la educación en nutrición clínica. Para ello se deberá promover un currículo mínimo en nutrición para pregrado y el reconocimiento de la nutrición clínica como especialidad. Conocimientos y competencias mínimas deberían ser impartidas en el pregrado de las carreras de salud. Las instancias correspondientes deberán acreditar la formación especializada y fomentar la educación continuada en el campo de la nutrición clínica.

El programa de implementación de la Declaración de Cartagena desarrollará herramientas que permitirán crear, promover y apoyar, al nivel que corresponda, $y$ bajo el nuevo paradigma de la educación en nutrición 
clínica. En el pregrado: fomentar la enseñanza de la nutrición clínica en las carreras de la salud (medicina, nutrición, enfermería, farmacia, etc.). En el posgrado de medicina y otras carreras de la salud: reconocer la nutrición clínica como especialidad clínica y no como subespecialidad o formación complementaria. Las instancias correspondientes: acreditar la formación especializada y fomentar la educación continuada en el campo de la nutrición clínica.

\section{PRINCIPIO \# 9}

\section{Fortalecimiento de las redes de nutrición clínica}

"Se deberá crear, promover y apoyar, al nivel que corresponda, actividades, programas y proyectos con el propósito de: a) promover en las instituciones de salud públicas y privadas el desarrollo del modelo de cuidado nutricional basado en detectar, nutrir, vigilar; b) fortalecer programas de educación en nutrición clínica; c) desarrollar y fortalecer líneas de investigación en nutrición clínica; d) impulsar la solidaridad y la cooperación en el desarrollo de programas para promover el cuidado nutricional y la lucha contra la malnutrición ${ }^{(1)}$."

\section{Contexto}

En el Principio \# 9 de la Declaración de Cartagena se reconoce la necesidad de fortalecer las redes de nutrición clínica. Este principio surge frente a la necesidad de aunar esfuerzos entre las distintas sociedades científicas, instituciones académicas y hospitalarias entre otros, para promover un mejor cuidado nutricional y la lucha contra la malnutrición.

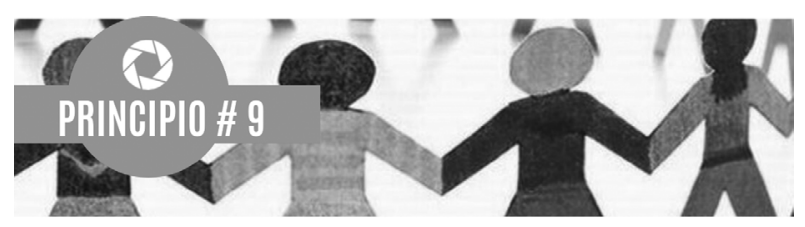

Se deberá crear, promover y apoyar, al nivel que corresponda, actividades, programas y proyectos con el propósito de:

a) promover en las instituciones de salud públicas y privadas el desarrollo del modelo de cuidado nutricional basado en detectar, nutrir, vigilar. b) fortalecer programas de educación en nutrición clínica.

c) desarrollar y fortalecer líneas de investigación en nutrición clínica.

d) impulsar la solidaridad y la cooperación en el desarrollo de programas para promover el cuidado nutricional y la lucha contra la malnutrición.

FELANPE

Declaración de Gartagena

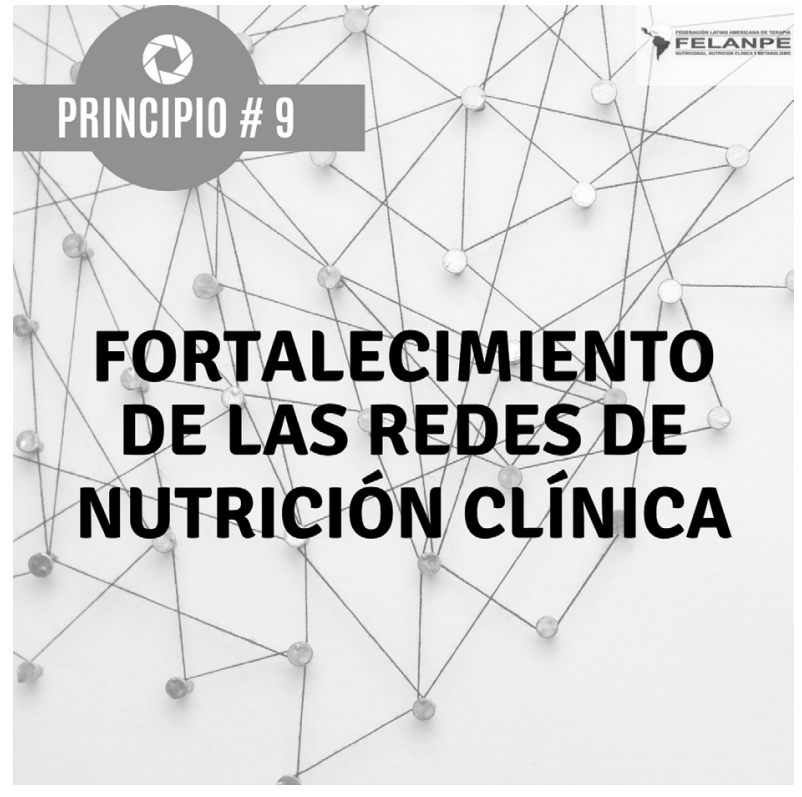

\section{Alcance}

El Principio \# 9 establece la necesidad de desarrollar redes de trabajo para así promover el cuidado nutricional y con esto, el desarrollo del modelo de cuidado nutricional basado en detectar, nutrir, vigilar; fortalecer programas de educación en nutrición clínica; c) desarrollar y fortalecer líneas de investigación en nutrición clínica; impulsar la solidaridad y la cooperación en el desarrollo de programas para promover el cuidado nutricional y la lucha contra la malnutrición.

\section{Perspectiva}

Las sociedades científicas que han firmado la Declaración se han comprometido a fomentar la creación de redes de trabajo para el fomento de la nutrición clínica. 


\section{PRINCIPIO \# 10}

\section{Creación de una cultura institucional que valore el cuidado nutricional}

"Se deberá crear, promover y apoyar, al nivel que corresponda, actividades, programas y proyectos con el propósito de sensibilizar a los médicos y otros profesionales de la salud sobre la importancia de la nutrición clínica; sensibilizar a la sociedad y a las instituciones sobre la problemática de la malnutrición y el derecho al cuidado nutricional; mostrar la evidencia científica que permita avanzar en la institucionalización del modelo de cuidado nutricional basado en detectar, nutrir, vigilar; promover la participación de la comunidad, los pacientes y las instituciones en la concretización del derecho al cuidado nutricional; propender por un cuidado nutricional justo y equitativo ${ }^{(1)}$."

\section{Contexto}

En el Principio \# 10 de la Declaración de Cartagena se reconoce la necesidad de crear una cultura institucional que reconozca el valor del cuidado nutricional basada en el respeto a los derechos humanos, en particular al derecho humano al cuidado nutricional. Este principio surge de la necesidad de crear conciencia sobre la desnutrición asociada a la enfermedad en los distintos espacios de atención en salud y el papel del cuidado nutricional.
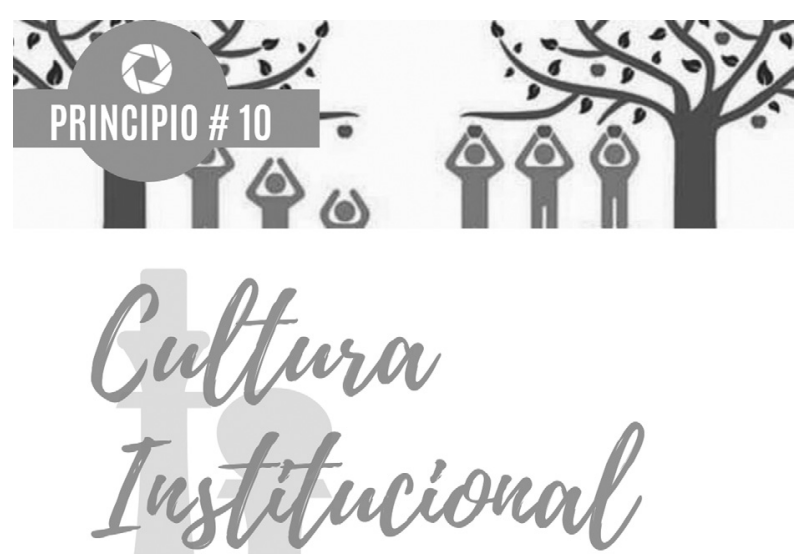

Se refiere a los valores y prácticas que orientan y dan sentido al quehacer de las instituciones.

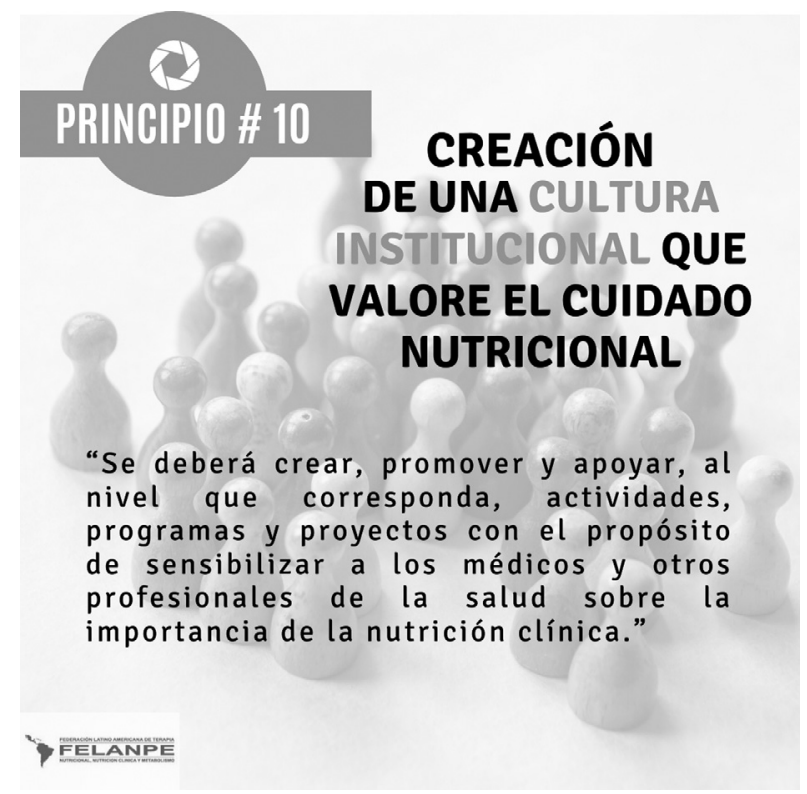

\section{Alcance}

El Principio \# 10 establece la necesidad de fomentar una cultura institucional que reconozca al cuidado nutricional como un derecho humano. Esto implica sensibilizar a la sociedad y a las instituciones sobre la problemática de la malnutrición y el derecho al cuidado nutricional; mostrar la evidencia científica que permita avanzar en la institucionalización del modelo de cuidado nutricional basado en detectar, nutrir, vigilar; promover la participación de la comunidad, los pacientes y las instituciones en la concretización del derecho al cuidado nutricional; propender por un cuidado nutricional justo y equitativo.

\section{Perspectiva}

Las sociedades científicas que han firmado la Declaración se han comprometido a reconocer el derecho al cuidado nutricional y a fomentar los principios y valores necesarios en las instituciones de atención en salud en distintos niveles

\section{Concepto clave}

La cultura institucional se refiere a los valores y prácticas que orientan y dan sentido al quehacer de las instituciones. 


\section{PRINCIPIO \# 11}

\section{Justicia y equidad en el cuidado nutricional}

"Se deberá crear, promover y apoyar, una agenda en salud pública justa y con equidad con el propósito de desarrollar los mecanismos para que toda persona enferma tenga disponibilidad, y acceso de manera estable, continua y oportuna a la terapia nutricional, así como también la correcta utilización de la terapia nutricional; promover la integración en los sistemas de salud del modelo de cuidado nutricional capaz de proveer terapia nutricional en condiciones de dignidad; promover el enfoque interdisciplinario y la creación de equipos de terapia nutricional; valorizar el reembolso y el pago de los servicios de cuidado nutricional ${ }^{(1)}$."

\section{Contexto}

En el Principio \# 11 de la Declaración de Cartagena se reconoce la necesidad de promover justicia y equidad en el cuidado nutricional. Este principio surge de la necesidad de promover que todas las personas enfermas reciban cuidado nutricional con las mismas condiciones y en igualdad de oportunidades.

\section{Alcance}

El Principio \# 11 establece la necesidad de fomentar legislaciones y políticas públicas justas en el campo de la nutrición clínica. Esto implica promover la integra-

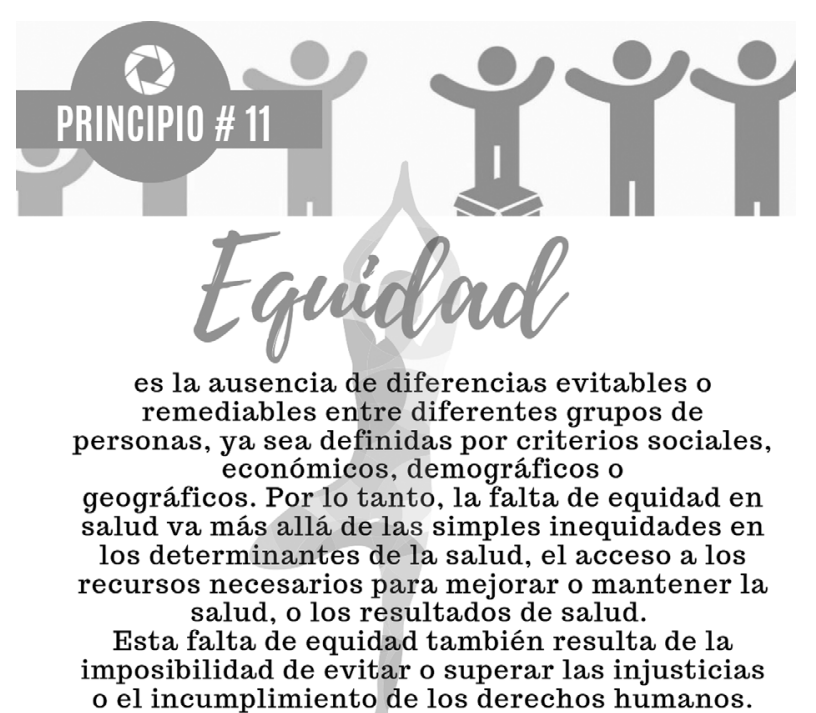

o el incumplimiento de los derechos humanos.

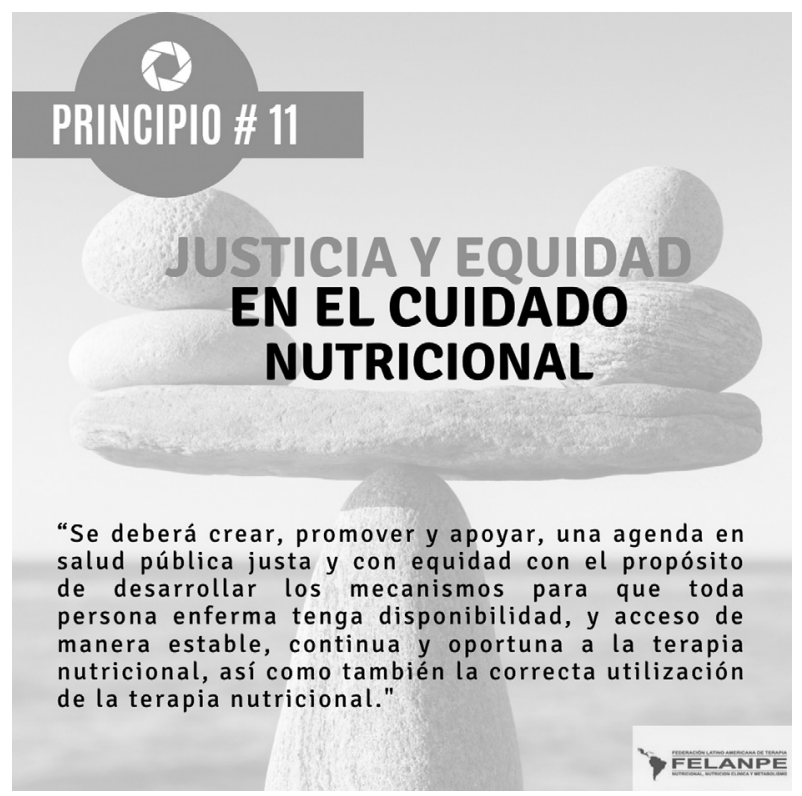

ción en los sistemas de salud del modelo de cuidado nutricional capaz de proveer terapia nutricional en condiciones de dignidad, justicia y equidad; promover el enfoque interdisciplinario y la creación de equipos de terapia nutricional; valorizar el reembolso y el pago de los servicios de cuidado nutricional, entre otros.

\section{Perspectiva}

Las sociedades científicas que han firmado la Declaración se han comprometido a promover legislaciones y políticas públicas en el campo de la nutrición clínica que brinden acceso al cuidado nutricional con justicia y equidad.

Consideramos que así es posible contribuir a alcanzar los Objetivos de Desarrollo Sostenible de Naciones Unidas 2 y 3 (ODS 2 y 3$)^{(4)}$ en particular los objetivos 2.2: "Para 2030, poner fin a todas las formas de malnutrición”, y 3.4: "Para 2030, reducir en un tercio la mortalidad prematura por enfermedades no transmisibles mediante la prevención y el tratamiento y promover la salud mental y el bienestar."

\section{Concepto clave}

La equidad es la ausencia de diferencias evitables o remediables entre diferentes grupos de personas, ya sea definida por criterios sociales, económicos, demográficos o geográficos. Por lo tanto, la falta de equidad en salud va más allá de las simples inequidades en los determinantes de la salud, el acceso a los recursos nece- 
sarios para mejorar o mantener la salud, o los resultados de salud. Esta falta de equidad también resulta de la imposibilidad de evitar o superar las injusticias o el incumplimiento de los derechos humanos.

\section{PRINCIPIO \# 12}

\section{Principios éticos, deontológicos y de transparencia de la industria farmacéutica y nutricional (IFyN)}

"Se deberá promover relaciones, basadas en políticas de ética y transparencia, entre las sociedades, colegios y asociaciones que defienden el derecho al cuidado nutricional y la IFyN, que exijan claridad y responsabilidad en las funciones de la IFyN para que puedan exhibir el más alto nivel de calidad de las soluciones y productos nutricionales; demostrar, por medio de científicos independientes a la IFyN, que las soluciones nutricionales creadas representan beneficio clínico objetivo y científicamente válido; tener programas de educación promovidos por la IFyN con el más alto valor científico y que estén libres de toda intención de comercialización de las soluciones nutricionales; que la interacción de la IFyN con las organizaciones profesionales y regulatorias esté estrictamente enfocada en la promoción de la mejor atención al paciente y el crecimiento científico constante ${ }^{(1)}$,"

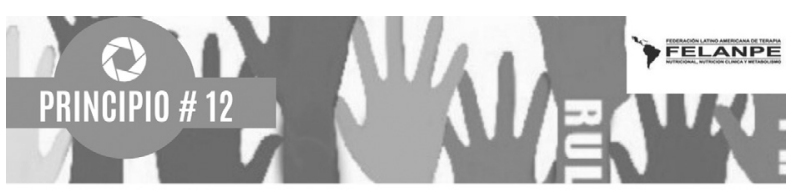

"Se deberá promover relaciones, basadas en políticas de ética y transparencia, entre las sociedades, colegios $y$ asociaciones que defienden el derecho al cuidado nutricional y la IFyN, que exijan claridad y responsabilidad en las funciones de la IFyN para que puedan demostrar el más alto nivel de calidad de las soluciones y productos nutricionales."

Declaraciōn de Gartagena

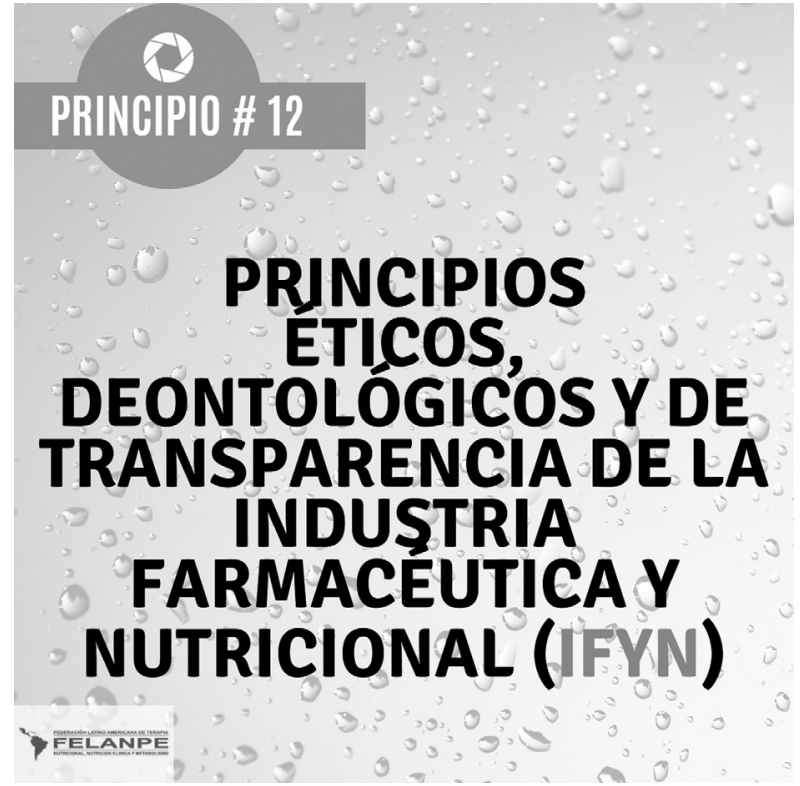

\section{Contexto}

En el Principio \# 12 de la Declaración de Cartagena se reconoce la necesidad de promover relaciones con la industria farmacéutica y nutricional basada en principios éticos, deontológicos y de transparencia. Este principio surge frente a la necesidad de evitar conflictos de intereses no esclarecidos y para reiterar que el bienestar de las personas debería tener prioridad con respecto al interés exclusivo de la industria farmacéutica.

\section{Alcance}

El Principio \# 12 establece la necesidad de promover relaciones con la IF\&A basada en principios éticos, deontológicos y de transparencia.

\section{Perspectiva}

Las sociedades científicas que han firmado la Declaración se han comprometido a promover relaciones con la IFyN basada en principios éticos, deontológicos y de transparencia. Para ello, cada sociedad, 
colegio y asociación deberá establecer políticas de ética, integridad y transparencia, reconociendo que la IFyN juega un papel esencial en la creación y comercialización de soluciones y fórmulas nutricionales para el paciente; y que contribuye a la educación del personal de salud (clínicos) en la prestación de nutrición y en la investigación nutricional.

\section{EL MANDATO DE LA DECLARACIÓN}

\section{PRINCIPIO \# 13}

\section{Llamado a la acción internacional}

"La FELANPE hace un llamado a las sociedades y organizaciones internacionales para unirse en la lucha contra la malnutrición y el respeto del derecho al cuidado nutricional. Los principios establecidos en el presente documento servirán de fundamento para acciones comunes.

La FELANPE insta a los Estados y al Consejo de Derechos Humanos de las Naciones Unidas a reconocer la presente Declaración y por lo tanto, el Derecho al Cuidado Nutricional como un derecho humano, y a que se garantice a todas las personas, especialmente a los enfermos con o en riesgo de desnutrición, acceso al cuidado nutricional y en particular a la terapia nutricional óptima y oportuna, con el fin de, entre otros, reducir las elevadas tasas de desnutrición hospitalaria y de morbi-mortalidad asociadas ${ }^{(1)}$."

En el Principio \# 13 se establece claramente el mandato de la Declaración de Cartagena. Allí se reconoce el derecho al cuidado nutricional como un derecho humano. También se reconoce que el beneficiario de ese derecho son los pacientes en cualquier ámbito de salud, quienes pueden reclamar el acceso al cuidado nutricional y en particular a la terapia nutricional óptima y oportuna. Los encargados de proteger este derecho son las sociedades y organizaciones internacionales que deben unirse en la lucha contra la malnutrición, y quienes deberán llegar a los gobiernos y legisladores políticos para crear legislaciones y políticas públicas en el campo de la nutrición clínica.
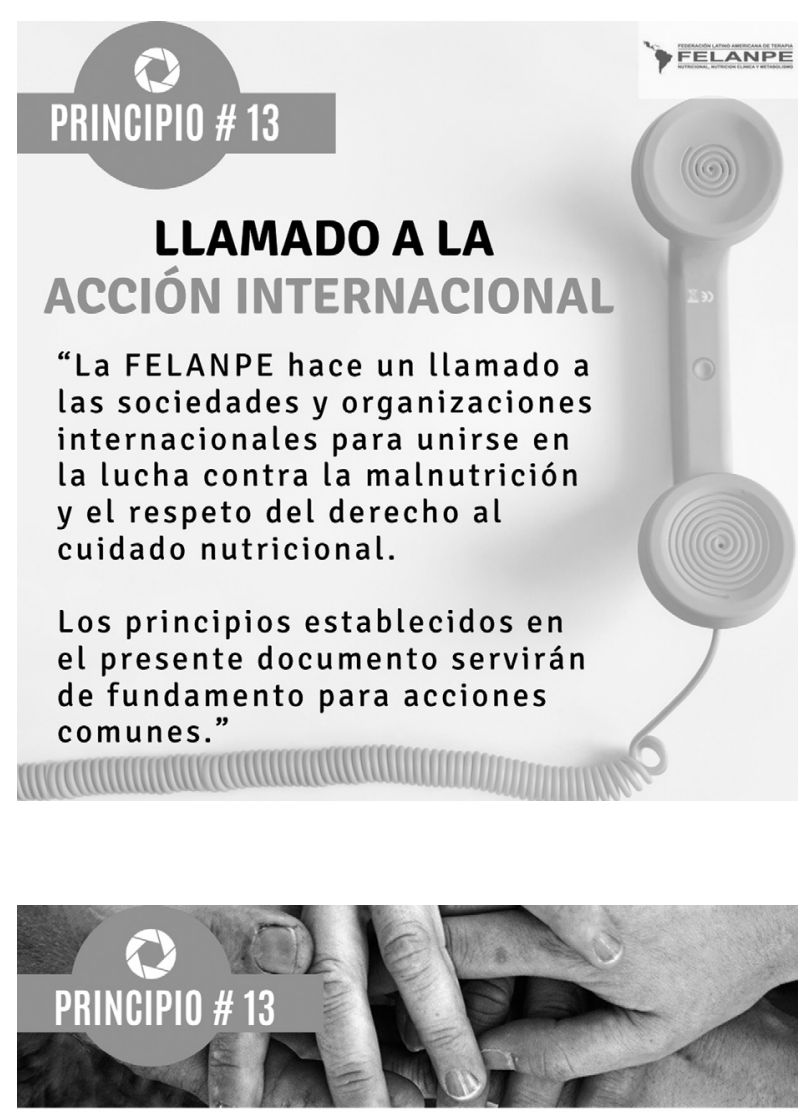

La FELANPE insta a los Estados y al Consejo de Derechos Humanos de las Naciones Unidas a reconocer la presente Declaración y por lo tanto, el Derecho al Cuidado Nutricional como un derecho humano, y a que se garantice a todas las personas, especialmente a los enfermos con o en riesgo de desnutrición, acceso al cuidado nutricional y en particular a la terapia nutricional óptima y oportuna, con el fin de, entre otros, reducir las elevadas tasas de desnutrición hospitalaria y de morbimortalidad asociadas. Declaración de Gartagena 


\section{Financiación}

El presente artículo no tuvo financiación.

\section{Conflicto de intereses}

Los autores declaran no tener conflicto de intereses.

\section{Declaración de autoría}

DC y MP diseñaron el articulo. Los autores declaran que revisaron el artículo y validaron su versión final. Las imágenes fueron diseñadas por Milena Puentes.

\section{Referencias bibliográficas}

1. Cardenas D, Bermúdez $\mathrm{CH}$, Echeverri S, Perez A, Puentes M, Lopez M, et al. DECLARACIÓN DE CARTAGENA.
Declaración Internacional sobre el Derecho al Cuidado Nutricional y la Lucha contra la Malnutrición. Nutr Hosp. 2019;36(4):974-98. http://dx.doi.org/10.20960/nh.02701

2. Cardenas D, Bermudez $\mathrm{CH}$, Echeverri S. Is nutritional care a human right? Clin Nutr Exp. 2019;26:1-7. https://doi. org/10.1016/j.yclnex.2019.05.002.

3. Organización de las Naciones Unidas para la Educación, la Ciencia y la Cultura. La Declaración de Bioética y Derechos Humanos. [Internet]. Paris: Unesco; 2005 [consultado el 8 de julio 2019]. Disponible en: http://portal.unesco.org/es/

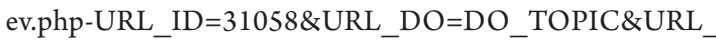
SECTION=201.html.

4. Organización de las Naciones Unidas. Objetivos de Desarrollo Sostenible. New York: ONU; 2015 [consultado el 8 de Julio 2019]. Disponible en: https://www.un.org/sustainabledevelopment/ es/energy/ [Internet]. 